\title{
REDUCTION IN DEFLECTION OF THE OVERHANGING COMMON SHAFT OF TRACTORS
}

\author{
Sumair Sunny ${ }^{1}$, Siddhesh Ozarkar², Sunny Pawar ${ }^{3}$ \\ ${ }^{\text {I} M a h a r a s h t r a}$ Institute of Technology, Maharashtra, India \\ ${ }^{2}$ Maharashtra Institute of Technology, Maharashtra, India \\ ${ }^{3}$ Maharashtra Institute of Technology, Maharashtra, India
}

\begin{abstract}
One of the few problems/glitches found in modern day tractors is the deflections of the overhanging common shaft. This shaft is normally overhanging on one side due to the fact that it provides hinge mountings for both left and right brake pedals. Due to this overhanging cantilever setup, undesired deflections arise which could cause plastic (or permanent) deformation of the shaft, reducing pedal efficiency as well as increasing the amount of force required to actuate the brake mechanism. Other than this the overall packaging of the tractor is asymmetric which is also undesired. Asymmetric packaging means two different packaging sets have to be manufactured so as to package the tractor for safe transport. This paper discusses various solutions for solving the above mentioned problem.
\end{abstract}

Keywords: Overhanging, Common-shaft, Deflections, PTO-Clutch, Plummer-block, Combi-brake, Latching, braking, pedal, reinforcement

\section{INTRODUCTION}

Let us summarize the problem statement as:

1. To reduce the deflections incurred on the pedal common shaft on the right hand side so as to maintain pedal efficiency during operation.

2. To reduce the overhang length so as to reduce common shaft's deflection as well as simplify packaging.

\subsection{Prerequisite Understanding:}

Before we jump to the solutions we must firstly understand the importance of the pedals and how they operate and control the tractor.

Modern farm tractors usually have four or five foot-pedals for the operator on the floor of the tractor.

The pedal on the left is the clutch. The operator presses on this pedal to disengage the transmission for either shifting gears or stopping the tractor. Some modern tractors have (or as optional equipment) a button on the gear stick for controlling the clutch, in addition to the standard pedal.

Two of the pedals on the right are the brakes. The left brake pedal stops the left rear wheel and the right brake pedal does the same with the right side. This independent left and right wheel-braking augments the steering of the tractor when only the two rear wheels are driven. This is usually done when it is necessary to make a sharp turn. The split brake pedal is also used in mud or soft soil to control a tire spinning due to loss of traction. If you are pulling a plow sometimes lightly braking one wheel will help you go straight. The operator can latch the brakes, then press the clutch pedal with left foot and any of the brake pedals with right foot to bring the tractor to a stop.

\subsection{Design Constraints}

1. Considering a rear wheel drive (2WD) tractor.

2. The force acting on each pedal is approximated to $600 \mathrm{~N}$. $(60 \mathrm{Kg} \times 9.81=588.6 \mathrm{~N})$ (At any given time during operation, only one or two such forces can be applied on any of the pedals on opposite sides, LHS \& RHS, as humans only have two feet).

3. Shaft Outer Diameter is 1 inch.

4. Shaft length and support positions: Refer diagram

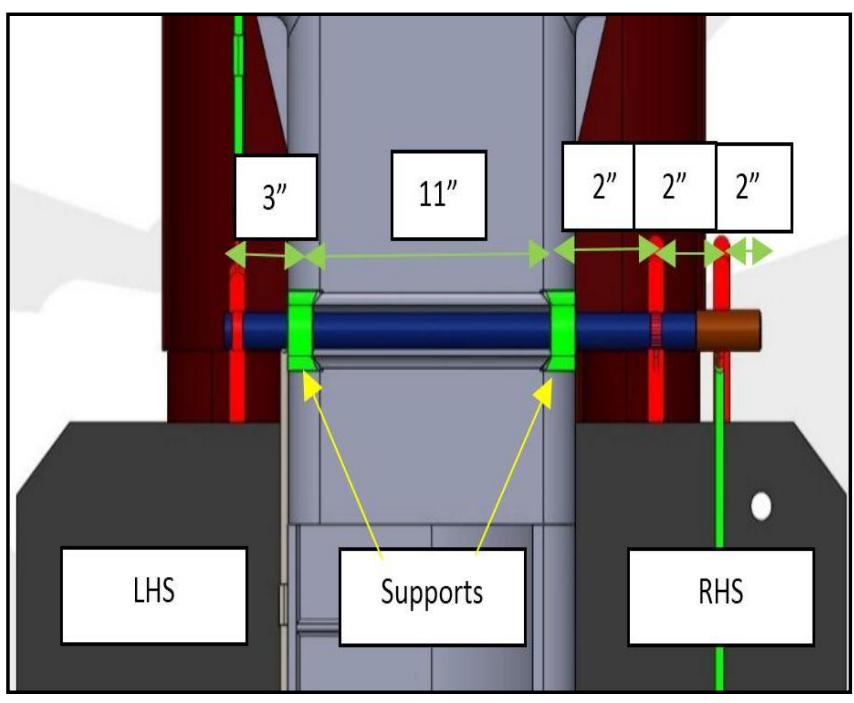

Fig -1: Common Shaft Arrangement 


\section{SOLUTIONS}

1. To reduce the deflections without changing overhang length.

a. Provide a Plummer block support at farthest end of the overhanging common shaft on right hand side.

b. Overhang reinforcement casing to support the overhang on RHS and prevent deflection.

2. To reduce the deflections by reducing overhanging length.

a. Couple left brake system with the clutch pedal and keep right brake system independent.

b. Button operated clutch on gear shifters, with independent right and left brake pedal on either side (eliminating clutch pedal).

c. Centrally located clutch with modified linkage. Left brake pedal on LHS \& right brake pedal on RHS, with latching mechanism.

d. "Combi-Brake" design (inspired from nongear two wheelers such as Honda Activa).

All the above mentioned solutions are explained in the subsequent sections:

\section{1 a: Plummer Block Support}

The unsupported overhanging part of the common shaft on the right hand side is prone to deflection. A force of $600 \mathrm{~N}$ can act on it and deflection of this shaft will reduce the braking efficiency.

Here the overhang length is not reduced. Instead a support is provided at the common shaft's farthest end. The Plummer block is mounted upside-down and is bolted onto the RHS (Right-Hand-Side) foot-rest panel as shown in figure below: For selecting a Plummer Block we need:

1. Bore diameter (shaft OD).....this we have constrained as 1 inch.

2. Dynamic load Capacity, so as to select a bearing capable of handling such a load $(600 \mathrm{~N})$.

Using formula:

$$
\mathrm{C}=\mathrm{P}\left(\mathrm{L}_{10}\right)^{p}
$$

Where, $\mathrm{C}=$ Dynamic load capacity $(\mathrm{N})$

$\mathrm{P}=\operatorname{Load}(600 \mathrm{~N} \times 1.5$ load application factor $=900 \mathrm{~N})$

$\mathrm{L}_{10}=$ Bearing Life (100 Million Revolutions)

$\mathrm{P}=0.3$ (roller bearing)

$\mathrm{C}=900(100)^{0.3}$

$\mathrm{C}=3582.96 \mathrm{~N}$

Using SKF OEMs we select a bearing and bearing housing (Plummer block) which can withstand the above calculated force. [4]
Table -1: SKF OEMs

\begin{tabular}{|l|l|}
\hline OEM & $\begin{array}{l}\text { SKF } \\
\text { NUMBER }\end{array}$ \\
\hline Plummer block housing & SNL 506-605 $\left(\mathrm{d}_{\mathrm{a}}=25.4 \mathrm{~mm}\right)$ \\
\hline Bearing & $22206 \mathrm{~K}$ \\
\hline
\end{tabular}

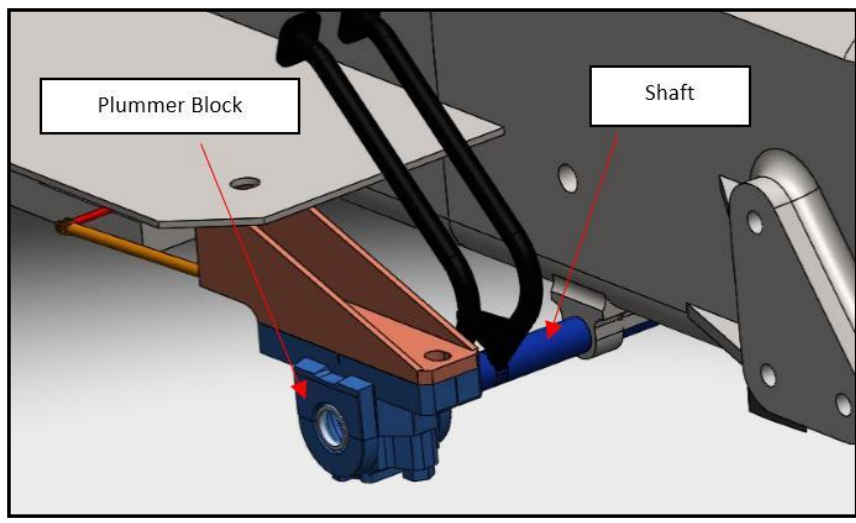

Fig -2: Plummer Block Mounting Arrangement

\section{1 b: Overhanging Reinforcement Casing}

Considering the overhanging shaft to be of length 6 inch on RHS. The left brake pedal is placed at 2 inch from support and the right brake pedal is placed at 4 inch from the support. When the driver presses the left brake pedal with a force of $60 \mathrm{Kg}$, assuming the length of pedal to be 12 inches, a torque of $600 * 304.8=182.88 \mathrm{KNmm}$ acts on the shaft .

Using Formula:

$$
\mathrm{Y}=(\mathrm{M} / 2 \mathrm{EI}) *\left(\mathrm{~L}^{2}-2 \mathrm{Lx}+\mathrm{x}^{2}\right)
$$

Where, $\mathrm{y}=\operatorname{deflection}(\mathrm{mm})$

$\mathrm{M}=$ couple $(182.88 \mathrm{KNmm})$

$\mathrm{E}=$ modulus of Elasticity $(210 \mathrm{GPa})$

$\mathrm{I}=$ moment of inertia of shaft $(\mathrm{pi} / 64) * \mathrm{~d}^{4}\left(\mathrm{~mm}^{4}\right)$

$\mathrm{L}=$ overhang length $(6$ inch $=152.4 \mathrm{~mm})$

$\mathrm{x}=$ distance of force acting on shaft from unsupported end of shaft $(4 \mathrm{inch}=101.6 \mathrm{~mm})$

Therefore the deflection on shaft when LH pedal is pressed is $0.0549 \mathrm{~mm}$.

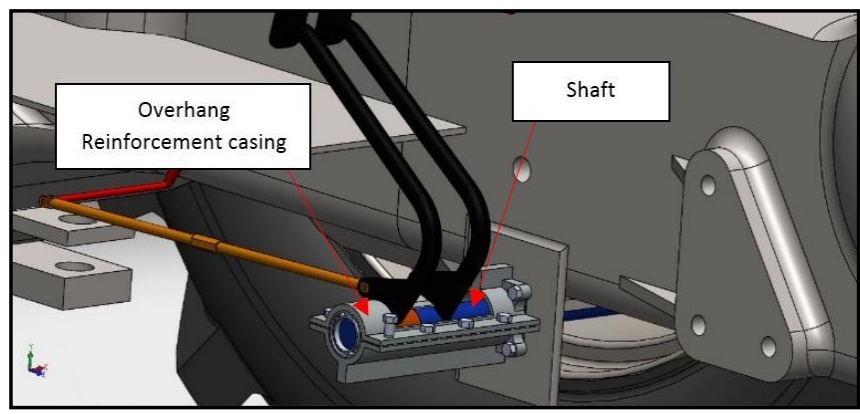

Fig -3: Overhanging Reinforcement Casing

Now when right brake pedal is pressed, same torque will be acting on the shaft but will act at a distance of 4 inch from 
the support. Therefore by similar calculation the deflection of shaft when right brake pedal is pressed is calculated as $0.219 \mathrm{~mm}$.

The deflection of the casing alone, when subjected to the same force is shown in figure below. [3] The maximum deflection (red portion) is $0.0889 \mathrm{~mm}$. This proves the inherent strength of the casing.

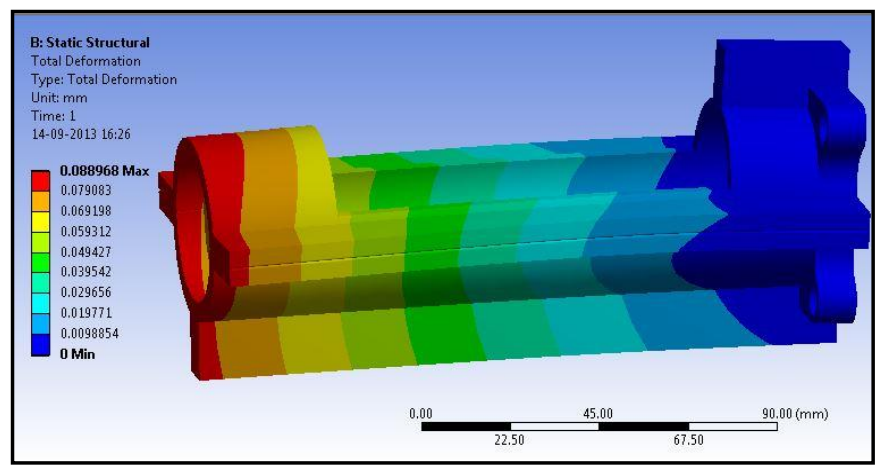

Fig -4: Strength-based analysis of Casing

When a Plummer block or reinforcement casing provides a support at the end of the overhanging shaft, the shaft is supported at both the ends. Therefore when the left brake pedal is pressed torque will be acting at 2 inch from left supported end and deflection of shaft is calculated similarly as $0.0018 \mathrm{~mm}$. Thus using Plummer block reduces the deflection from $0.0549 \mathrm{~mm}$ to $0.0018 \mathrm{~mm}$.

\section{2 a: Couple Left Brake System with the Clutch}

\section{Pedal and keep Right Brake System Independent}

In this solution the clutch pedal also operates as the left brake pedal. (This is done by attaching the LHS braking link to the clutch pedal). As a result we have one less pedal to incorporate on the RHS. Hence the overhanging common shaft's length is reduced and hence the deflection is also reduced.

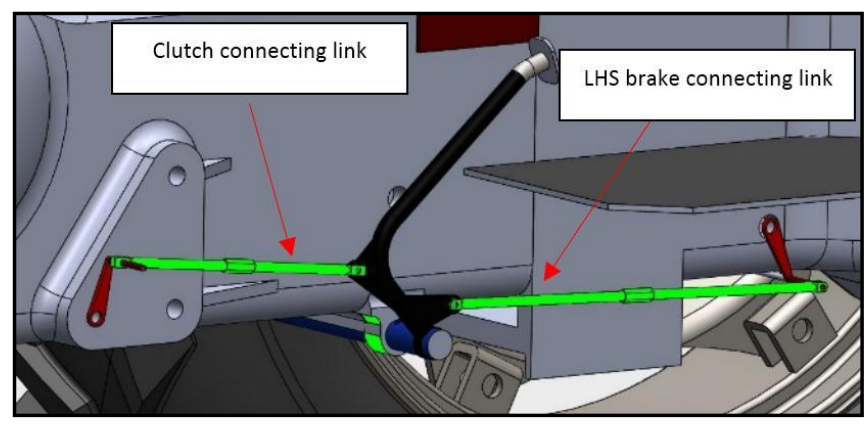

Fig -5: LH Brake \& Clutch Coupled

This design offers independent braking only to the Right Rear wheel. Hence the tractor can make tight right hand turns when only the right brake pedal is pressed. In case the clutch is pressed the tractor will stop as the transmission will get disengaged and further the left brake also gets actuated.
- The incapability of the tractor to make sharp left hand turns is the only short coming of the design.

\section{Advantage:}

- Apart from the shortened common shaft, another advantage would be reduced cost as one less pedal has to be made.

\section{2 b: Couple Button Operated Clutch on Gear}

\section{Shifters, With Independent Right \& Left Brake}

\section{Pedal on Either Side (Eliminating Clutch Pedal)}

In many modern day tractors electronic controls are replacing conventional mechanisms. This solution is inspired from John Deere PTO control. [5] Here clutching can be done by electrical and hydraulic means, rather than the conventional links \& mechanisms. As a result we can eliminate the clutch pedal. We can place the left brake pedal on LHS and Right Brake Pedal on RHS. Thus the overhang length of common shaft gets reduced. Since both the brakes are independent the tractor can take tight turns on both LHS and RHS.

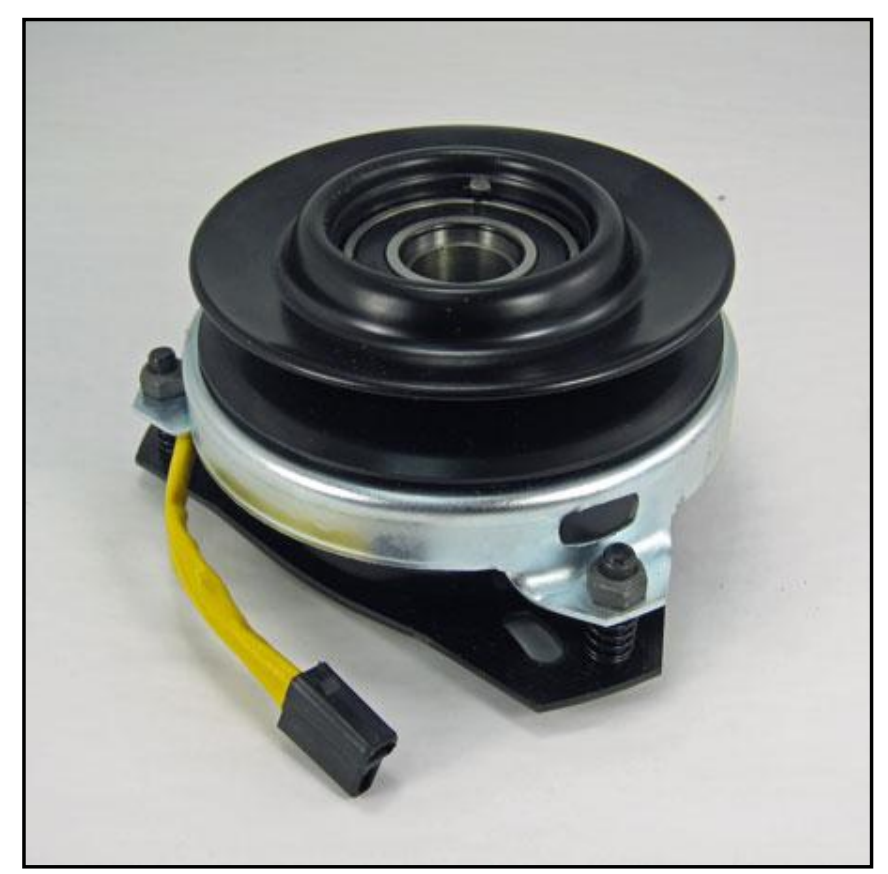

Fig -6: John Deere Electromagnetic PTO Clutch Assembly

\section{Disadvantages:}

- $\quad$ System is more expensive.

- In case of electrical failure the tractor will be stuck as there is no way to put it into gear, (it can be stopped by pressing brakes and stalling). It might involve slight redesign/modification of clutch system.

\section{Advantage:}

- Reduced overhang of common shaft.

- One less pedal, as clutch pedal is eliminated, thus reducing cost.

\section{Disadvantage:}




\section{2 c: Centrally Located Clutch with Modified}

\section{Linkage. Left Brake Pedal on LHS \& Right Brake \\ Pedal on RHS, With Latching Mechanism}

This solution is an alternative which builds on the short comings of solution $2 \mathrm{~b}$.

Here the clutch pedal is centrally mounted (i.e. between LHS and RHS), and it is connected to the clutch system by a modified linkage.

Only the brake pedals are attached on the common shaft; Left brake pedal on LHS and Right brake pedal on RHS). Hence common shaft length is reduced. Both brake pedals are independent of each other.

\section{Need for a Latching Mechanism}

Since there are now three pedals and humans only have two feet trying to stop the vehicle would become very difficult or instead one brake may not get used.

To stop the vehicle one foot will have to operate the clutch pedal. Thus now the driver can only press one of the brake pedals with his/her other foot.

A solution for this would be a Latching Mechanism. The right brake pedal is pinned to the common shaft and rotates with the common shaft. The left brake pedal is only pivoted on the common shaft with the help of a bush, and its rotation is independent of that of the common shaft.

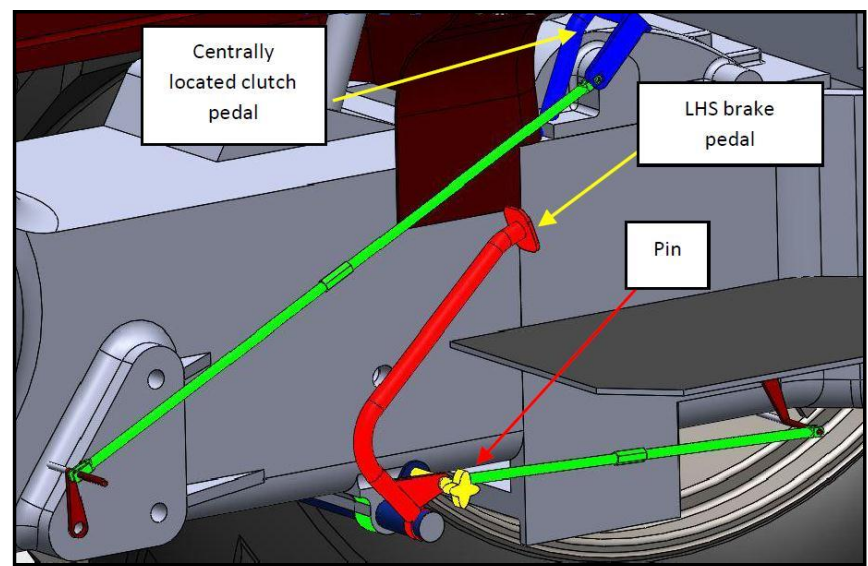

Fig -7: Centrally Located Clutch with Latching Mechanism

As seen from the figure there is a latching bracket attached to the shaft on the LHS. When the left brake pedal is pinned to this bracket, the brake pedal is no longer independent of the common shaft and will now rotate with the common shaft. Hence as the right brake pedal gets pressed both the brakes (LHS \& RHS) get actuated.

The Latching pin is simply a threaded screw which can turned clockwise to latch or counter clockwise to unlatch. This cannot be done during operation.
As a fail-safe if the system is unlatched and the user wants to stop the tractor another technique is to first clutch and shift into neutral and then leave the clutch pedal and press both brakes.

\section{Disadvantage}

- Latching cannot be done during operation.

- $\quad$ Pedal mounting will take some getting used to or may not favour all users as normally we use clutch pedal on the left of our brake pedals, not between the brake pedals.

\section{Advantage}

- $\quad$ Both brakes are independent so taking tight turns is possible on both LHS and RHS.

- Since there are only two pedals on the common shaft, overhang length gets reduced.

\section{2 d: "Combi-Brake" Design}

This solution is inspired from non-geared two wheelers such as the Honda Activa.

On the LHS we have a clutch pedal pivoted on the common shaft (using a bush) as well as a threaded pin screwed into the common shaft (perpendicular to the shaft surface in plane with the right brake pedal). On the RHS we have the right brake pedal keyed to the common shaft. Thus as the brake pedal rotates, the common shaft also rotates, and the pin on LHS rotates in the same direction as the right brake pedal.

As seen in the figure below, the right brake connecting link is connected to the right brake pedal and the left brake connecting link is connected to the pin on the LHS.

Thus as the user presses the right brake pedal both LHS and RHS brakes get actuated. The left foot only operates the clutch.

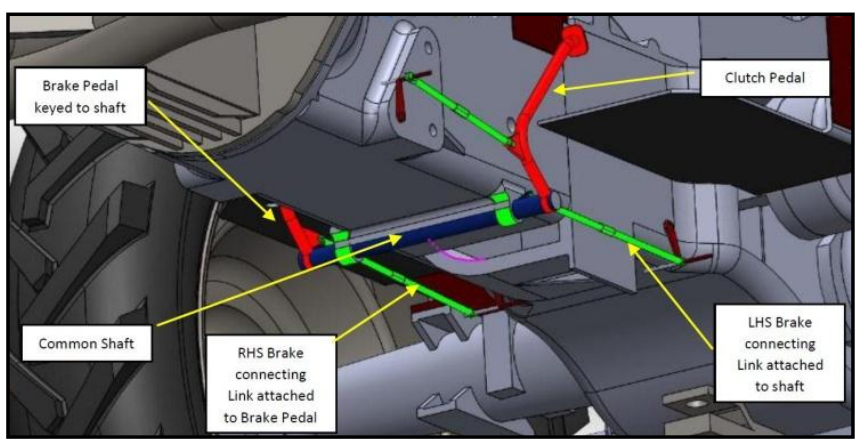

Fig -8: Combi-Brake Design

\section{Disadvantage:}

- A major drawback of this design is that the brakes are not independent and so taking tight turns on either side is not possible.

\section{Advantage:}

- $\quad$ Simple to design \& easy to maintain. 
- $\quad$ Simple to operate.

- One pedal is reduced so cost goes down slightly.

- Common shaft overhang length is reduced.

\section{CONCLUSIONS}

From the first set of solutions we can conclude that the overhanging shaft's deflection can be reduced to permissible limits by means of additional accessories such as the Plummer block and the Reinforcement casing. These solutions however, do not solve the packaging problem. They only deal with the deflections. These solutions come with the perk that they can be easily applied on models that have already been manufactured. They can be seen as additional accessories. There is not much change in the overall design. The packaging problem however, still remains.

The second set of solutions involves rearrangement of the brake and clutch pedals and their respective mechanisms. Here the overhanging shaft length does get reduced which also solves the deflection problems but each solution comes with a compromise.

Thus we would suggest one of the solutions from the first set. Either of them could be applied depending on the tractor model. These solutions can be seen as easy modifications which could be made at any time, even on tractors that have already be manufactured.

The main reason why we suggest the first set of solutions is because it doesn't change the way tractors are driven, so the end user doesn't have to adjust to a different or unfamiliar system.

\section{REFERENCES}

[1]. Design Data Hand Book, PSG Coimbatore.

[2]. Design of Machine Elements, 3rd Edition, V.B. Bhandari, McGraw Hill Publications.

[3]. ANSYS Workbench 14.0, Sham Tickoo, Dreamtech Publications.

[4]. www.skf.com

[5]. www.greenpartstore.com/John-Deere-ElectromagneticPTO-Clutch-Assembly-Warner-AM122969.html

\section{BIOGRAPHIES}

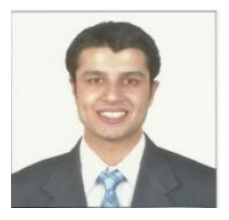

Sumair Sunny, Mechanical Engineering Graduate, M.I.T., Pune

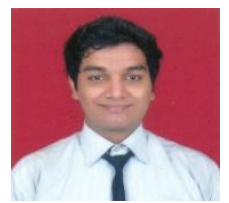

Siddhesh Ozarkar, Mechanical Engineering Graduate, M.I.T., Pune

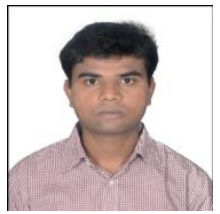

Sunny Pawar, Mechanical Engineering Graduate, M.I.T., Pune 